\title{
Prognostic implications of myocardial creatine kinase and cardiac troponin in coronary artery bypass surgery
}

\section{Implicação prognóstica da creatino-quinase miocárdica e troponina na revascularização} do miocárdio

Fábio P. TANIGUCHI ${ }^{1}$, Paulo M. PÊGO-FERNANDES ${ }^{1}$, Fabio B. JATENE ${ }^{1}$, Karina L. KWASNICKA ${ }^{1}$, Célia M. C. STRUMZ ${ }^{1}$, Sérgio A. OLIVEIRA ${ }^{1}$

RBCCV 44205-639

Abstract

Objectives: To evaluate the prognostic implications of myocardial creatine kinase and troponin I (cTn I) in blood samples from the coronary sinus of patients submitted to coronary artery bypass surgery both with and without ischemic preconditioning.

Methods: From October 1998 to May 1999, 35 patients with coronary artery disease who were submitted to coronary artery bypass surgery were studied. Samples containing creatine kinase and cTn I were obtained from the great cardiac vein during surgery at the onset of cardiopulmonary bypass, at the end of the first anastomosis, and at the end of cardiopulmonary bypass. In May 2002, 29 patients were evaluated in regards to the angina functional class, congestive heart failure, number of hospitalizations, myocardial infarction and death. There were 15 patients in the Preconditioned group and 14 in the Control group. Each group was subdivided into patients with and without cardiovascular symptoms.
Results: The Control and Preconditioned groups were not significantly different in relation to frequency of cardiovascular symptoms. There were progressive increases of the creatine kinase and cTn I levels at different Interval s of the study. The cTn I in the Preconditioned group was 1.21 $\pm 0.64 \mathrm{ng} / \mathrm{mL}$ and $3.19 \pm 3.21 \mathrm{ng} / \mathrm{mL}$ in the Control group $(\mathbf{p}<0.05)$. The Control group with symptoms had the highest level for cTn I of $5.07 \pm 3.69 \mathrm{ng} / \mathrm{mL}$, significantly higher than all other groups $(\mathbf{p}<0.05)$.

Conclusions: The Preconditioned group had the lowest level of cTn I. The cTn I may be a marker for late evolution in patients submitted to coronary artery bypass surgery.

Descriptors: Myocardial revascularization. Myocardial ischemic preconditioning. Myocardial ischemia, physiology. Troponin.

Work performed in the Heart Institute of the Hospital das Clínicas of the Medical School, University of São Paulo, São Paulo, SP, Brazil 1 - Heart Institute of the Hospital das Clínicas of the Medical School, University of São Paulo.

Correspondence address: Paulo M. Pêgo-Fernandes. Av Dr. Enéas de Carvalho Aguiar, 44, Cerqueira César, São Paulo, SP, Brazil. CEP 05403-900

Phone: (11) 3069-5234. 


\author{
Resumo \\ Objetivo: Avaliar a implicação prognóstica da dosagem da \\ creatino-quinase miocárdica (CKMB) e Troponina I (cTn I) \\ em amostras no seio coronariano, na evolução de pacientes \\ submetidos a revascularização do miocárdio (RM), com e sem \\ o pré-condicionamento isquêmico. \\ Método: Entre outubro de 1998 e maio de 1999, 35 pacientes \\ com insuficiência coronariana foram submetidos a RM foram \\ estudados. No intra-operatório foram coletadas amostras do \\ seio coronariano para dosagem de CKMB e cTn I. Os \\ momentos de coleta foram: momento 1-no início da circulação \\ extracorpórea (CEC), momento 2- após a primeira anastomose \\ e momento 3- no final da CEC. Em maio de 2002, 29 pacientes \\ foram avaliados quanto aos sintomas para classe funcional \\ de angina e de insuficiência cardíaca congestiva, número de \\ internaç̃es hospitalares, ocorrência de infarto agudo do \\ miocárdio e morte. Os 29 pacientes estavam distribuídos em \\ dois grupos: 15 no grupo pré-condicionamento e 14 no grupo
}

\section{INTRODUCTION}

Myocardial infarction after coronary artery bypass grafting $(\mathrm{CABG})$ is recognized as a complication in the evolution of the patient giving an increase in surgical morbid-mortality rates $[1,2]$

Myocardial lesion has been demonstrated by means of myocardial creatine-kinase (CKMB), which is related to cardiac muscle necrosis, as well as by troponin I (cTn I), which is one of the sub-units of troponin. Troponin is a regulating molecule of the actin-myosin complex in the cardiac cell and is highly specific for the determination of myocardial lesion $[3,4]$. Determination of the peri-operative increases of cardiac enzymes is related to an increase in mortality.

Myocardial protection can be incremented by ischemic pre-conditioning of the heart, which is an endogenic mechanism of myocardial protection in which short periods of ischemia confer myocardial protection in subsequent periods of ischemia [5].

The aim of this work is to evaluate the prognostic implications of CKMB and CTn I, in samples collected from the coronary sinus in the intra-operative period, in the evolution of patients submitted to $\mathrm{CABG}$, using the operative technique of intermittent aortic clamping, with and without ischemic pre-conditioning.

\section{METHOD}

In the period from October 1998 to May 1999, 35 patients suffering from coronary insufficiency with indication for controle. Cada grupo também foi subdividido em: pacientes com sintomas cardiovasculares e assintomáticos.

Resultados: Os grupos controle e pré-condicionado não apresentaram diferença estatística para a presença de sintomas cardiovasculares. Houve aumento progressivo nos valores de CKMB e cTn I nos diferentes momentos de coleta. A cTn I no grupo pré-condicionado foi de $1,21+0,64 \mathrm{ng} / \mathrm{ml} \mathrm{e}$ $3,19+3,21 \mathrm{ng} / \mathrm{ml}$ no grupo controle $(\mathbf{p}<0,05)$. O grupo controle sintomático foi o que apresentou valor de cTn I mais elevado, de $5,07+3,69 \mathrm{ng} / \mathrm{ml}$, estaticamente maior dos outros grupos $(\mathbf{p}<\mathbf{0 , 0 5})$.

Conclusões: Houve menor liberação de c Tn I no grupo pré-condicionado. A cTn I pode ser um marcador de evolução tardia em pacientes submetidos a RM.

Descritores: Revascularização miocárdica. Précondicionamento isquêmico miocárdico. Isquemia miocárdica, fisiologia. Troponina.

CABG were prospectively divided into two random groups [6]. The first group, denominated the Control group, was operated on under systemic hypothermia at $32{ }^{\circ} \mathrm{C}$ with intermittent aortic clamping and using cardiopulmonary bypass (CPB). In the second group, denominated Preconditioned group, two short periods of aortic clamping with an interval of reperfusion between, before the conventional intermittent clamping, was added to the procedures described for the Control group.

Inclusion criteria for the study were: pre-operative ejection fraction greater than $30 \%$; not being a re-operation; having the involvement of at least two coronary arteries; the use of CPB; not to have unstable angina at the time of operation; not to be in the phase of acute myocardial infarction and not to require other associated corrective surgery such as valve surgeries including valve replacement, aneurysmectomy of the left ventricle or ventriculotomies.

In all patients, cannulation of the ascending aorta and the two vena cavas was utilized for CPB. Then, a $3 \mathrm{M}$ catheter, normally employed in retrograde cardioplegia, was introduced in the coronary sinus, from which blood samples were withdrawn. The surgeon and other members of his medical team discovered at this point in which group the patient was to be included, the Control or the Preconditioned group.

After systemic cooling to $32{ }^{\circ} \mathrm{C}$, aortic clamping was initiated. In the Control group, during each aortic clamping, anastomosis between the graft and the coronary artery to be revascularized was performed. For each 3-4 minutes of clamping, 1 minute of reperfusion was made. This procedure was utilized both for distal and proximal anastomoses. In 
the ischemic Preconditioned group two periods of aortic clamping of 3 minutes, alternated with 2 minutes of reperfusion were performed. After the second interval of reperfusion, the operation was performed identically to the Control group. During the last anastomosis, systemic warming of the patient was initiated. At the end of the las anastomosis, the aorta was de-clamped and subsequently the $\mathrm{CPB}$ was removed.

Blood samples from the coronary sinus were collected at three time intervals: at the start of CPB at normothermia (Interval 1), immediately after the first anastomosis at $32^{\circ} \mathrm{C}$ (Interval 2) and at the end of CPB, again at normothermia (Interval 3). These samples were sent for measurement of cTn I and CKMB

After release from hospital, the patients were accompanied by their cardiologists. Of the 35 patients, 29 patients were found and re-evaluated in May 2002 by means of an interview in relation to cardiac events which were experienced after the CABG surgery. Of the 29 patients, 14 were from the Control group and 15 from the Preconditioned group. The patients were also evaluated in respect to angin using the functional class symptoms described by the Canadian Cardiovascular Society (CCS) criteria, in respect to congestive heart failure symptoms using the classification of the New York Heart Association, the number of hospitalizations, occurrence of acute myocardial infarction after the CABG operation and death due to heart failure.

The Institution's Research Ethics Committee of the Hospital das Clinicas of the University of São Paulo Medical School approved this study.

\section{Statistical analysis}

Fisher exact test was employed to compare the two groups in relation to the homogeneity of the proportions. The Student t-test was employed to compare the groups in relation to quantitative data. Friedman test was utilized to compare the measurements of cTn I and CKMB at the different time intervals. The data are expressed as a mean \pm standard deviation. The established significance level was of $5 \%$.

\section{RESULTS}

The 14 patients of the Control group presented with an age of $63.71 \pm 9.76$ and in the 15 of the Preconditioned group the mean age was $67.73 \pm 8.83$ years ( $\mathrm{p}$-value $>0.05$ ). The groups were compared in respect to the gender giving a $\mathrm{p}$ value $>0.05$

There were no significant differences between the two groups of patients in relation to the weight, height, incidence of diabetes mellitus, incidence of systemic arteria hypertension, presence of previous myocardial infarctions, presence of branch obstructions evidenced using electrocardiography, previous unstable angina, confirming homogeneity between the groups.

A mean of 3.28 grafts per patient was performed in the Control group and 3.13 grafts per patient in the Preconditioned group ( $p$-value $>0.05$ ). In relation to the intraoperative characteristics, including the maximum time of aortic clamping, the sum of the total aortic clamping times, number of revascularized coronary arteries, grafts used, time of CPB and time of anesthesia, there was also no statistical difference between the two groups. In the postoperative period, no patients presented with signs of perioperative myocardial infarction.

The mean time of the follow up of the patients in the Control group was $40.8 \pm 1.7$ months and $38.6 \pm 4.3$ months for the Preconditioned group ( $\mathrm{p}$-value $>0.05$ ).

In the late postoperative follow-up period, the Control group presented with 11 patients $(78.5 \%)$ free from angina. Two patients presented with angina CCS functional class II and one presented with CCS functional class IV. In the Preconditioned group, 13 patients (86.6\%) evolved without angina. One patient evolved with angina CCS functional class I and another with CCS functional class III. In relation to congestive heart failure, 3 patients of the Control group presented with NYHA functional class II and one patient functional class IV whilst in the Preconditioned group one patient presented with functional class III (Figure 1).

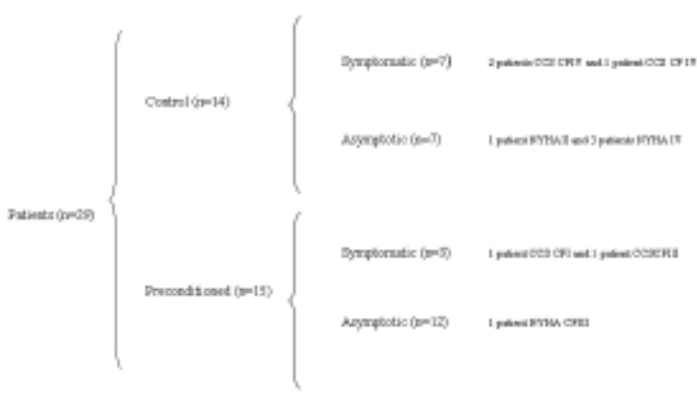

Fig. 1 - Composition of the groups in relation to the cardiac events

In respect to the number of hospitalizations after surgery, one patient from the Control group suffered from myocardia infarction and another from unstable angina. In the Preconditioned group, two patients were hospitalized for myocardial infarction.

The two groups did not present with significant differences in relation to the presence of cardiovascular symptoms during the follow up of the patients ( $\mathrm{p}$-value $=0.09$ ).

The Control group had a statistically greater increase of $\mathrm{cTn}$ I at the end of CPB, compared to the Preconditioned group. 
The cTn I at Interval 3 was $1.21 \pm 0.64 \mathrm{ng} / \mathrm{mL}$ for the Preconditioned group and $3.19 \pm 3.21 \mathrm{ng} / \mathrm{mL}$ ( $\mathrm{p}$-value $<0.05$ ), for the Control group (Figure 2).

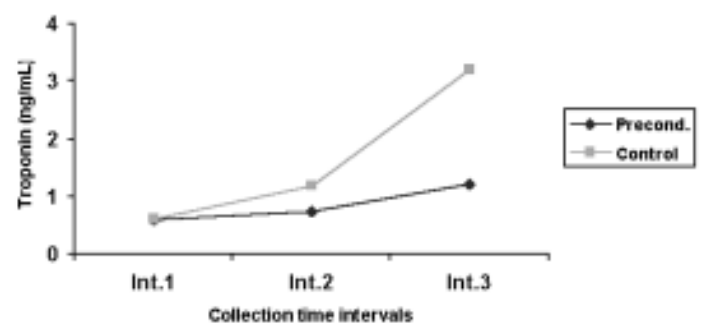

Fig. 2 - Evolution of Troponin I at the different time intervals of collection for the Control and Precondition groups

Int. 1 - Initiation of cardiopulmonary bypass

Int. 2 - After the first anastomosis

Int. 3 - At the end of cardiopulmonary bypass

There was no significant difference for the CKMB at Interval 3 between the groups $(23.73 \pm 7.92 \mathrm{U} / \mathrm{L}$ and $27.57 \pm$ $6.01 \mathrm{U} / \mathrm{L}$ for the Preconditioned and Control group respectively - p-value $<0.05$ ).

Both the Control and Preconditioned groups were split in patients with and without cardiovascular symptoms, denominated as symptomatic and asymptomatic respectively. The groups were studied for the behavior of $\mathrm{CKMB}$ and $\mathrm{cTn} \mathrm{I}$ at the three time intervals determined by the collection of samples from the venous sinus.

All the groups were homogenous in relation to the intraoperative characteristics, including the maximum aortic clamping time, sum of the aortic clamping times, number of coronary arteries revascularized, grafts employed, CPB time and time of anesthesia, there were no significant differences between the groups.

For CKMB, the groups presented with a statistically significant difference $(p$-value $<0.05)$ in at least one of the time intervals of each group. At interval 3, there was an increase of CKMB in all the groups but there was no significant difference between the groups. In the symptomatic Control group, an early increase of CKMB was observed at interval 2, differentiating the behavior of this group from the others (Figure 3 ).

The behavior of $\mathrm{cTn}$ I was a progressive increase in all the groups, giving a statistical difference between the intervals. In the symptomatic Control group, there was an increase of cTn I at intervals 2 and 3 in relation to the other groups, with a statistically significant difference ( $p$-value $<$ 0.05)-(Figure 4).

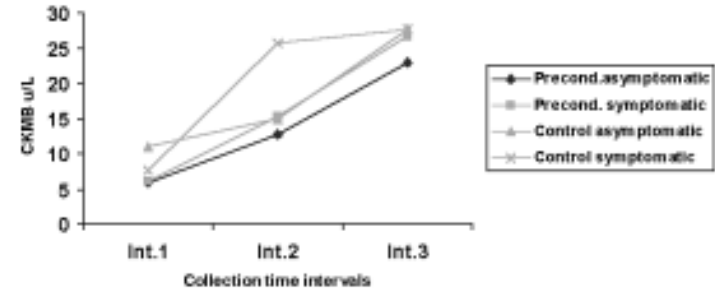

Fig. 3 - Evolution of CKMB at different time intervals of collection for the different groups

Int. 1 - Initiation of cardiopulmonary bypass Int. 2 - After the first anastomosis

Int. 3 - At the end of cardiopulmonary bypass

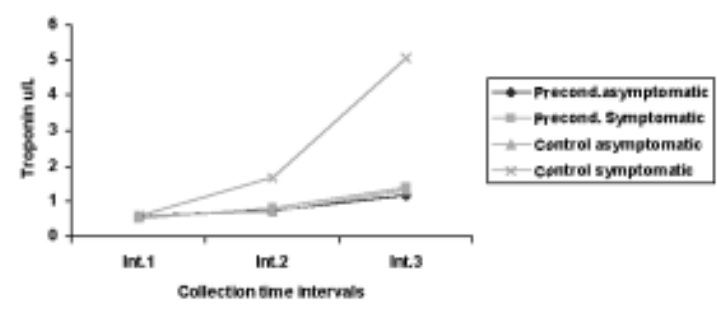

Fig. 4 - Evolution of Troponin I at different time intervals of collection for the groups

Int. 1 - Initiation of cardiopulmonary bypass

Int. 2 - After the first anastomosis

Int. 3 - At the end of cardiopulmonary bypass

\section{COMMENTS}

In the postoperative evolution of $\mathrm{CABG}$, perioperative myocardial infarction presents as an important complication, increasing the morbid-mortality rates in the late evolution $[1,2]$.

The incidence of post-operative myocardial infarction is variable, depending on the different diagnostic methods utilized. The diagnosis of perioperative infarction by serial electrocardiography, echocardiography and by enzymatic markers of myocardial lesion suffer due to the lack of sensitivity and specificity. Postoperative serial electrocardiography has limited sensitivity and does not 
measure the lesion. Echocardiography might not be useful in patients who already present with abnormal examinations. Levels of myoglobin and creatine kinase are altered by thoracotomy [7].

Troponin I has been used in the determination of myocardial necrosis. It is an inhibiting molecule of adenosine triphosphate of the actin-myosin complex in cardiac muscle cells. It is highly specific to determine myocardial lesion $[3,4]$ and it is about 13 times more abundant in the myocardium than CKMB [8].

Other forms of troponin are identifiable as troponin $\mathrm{C}$ and troponin $\mathrm{T}$ however, cTn I is the only one to by exclusively isolated in the cardiac muscle, withou presenting with interference of other sources of troponin such as the skeletal muscles. The presence of cTn I has not been demonstrated in healthy individuals, in marathon runners, in individuals suffering from skeletal muscle diseases or after orthopedic surgery [9].

The liberation of cTn I in cardiac surgery with aortic clamping is proportional to the time of ischemia. Etievent et al. [10] demonstrated a positive correlation between time of ischemia and liberation of cTn I in patients who were submitted to aortic valve replacement and who did not present with coronary disease. The groups of patients in our cohort presented with times of ischemia without statistical differences.

SWAANENBURG et al. [11] demonstrated that CABG with CPB provokes an increase in cTn I, even in patients who do not present electrocardiographic alterations in the post-operative period. BONNEFOY et al. [4] observed that patients who evolve with new Q-waves on the 12lead electrocardiogram in the post-operati==ve period, were patients who presented with values of cTn I and troponin $\mathrm{T}$ at 6,12 and 24 hours, collected in periphera veins, significantly lower than pre-aortic clamping. The patients in our group were submitted to a routine postoperative electrocardiography. No new Q-waves were evidenced in our patients.

Reversible myocardial ischemia can cause a functional loss in the cellular membrane and liberation of cytosolic enzymes without cellular necrosis or loss of relevant function $[12,13]$.

In a recent publication, COSTA et al. [14] reported a relationship between an increase in CKMB and risk of greater cardiac events (death, myocardial infarction, reoperation and cerebrovascular events). The samples of CKMB were collected at 6,12 and 18 hours after the surgery and if there was an increase, new samples were collected until identifying the peak value. The patients were divided into four groups: normal CKMB, CKMB levels increased by between one and three times, between three and five times and greater than five times. The level of CKMB was a predictor of late events, particularly in the group that presented a peak level greater than five times the normal.

The prognostic implication of the elevation of intraoperative cTn I was considered by JENKINS et al. [15], when he proposed that the demonstration of the increase of cTn I is a consequence of myocardial lesion. GREENSON et al. [16] reported that the peak of cTn I demonstrates the risk of cardiac events in a significantly better manner than the peak of CKMB, in patients submitted to CABG. In this study, the patients who presented with an increase of cTn I in the first two days after surgery evolved with the greatest number of cardiac events, and greatest times of mechanical ventilation, of intensive care unit and the longest hospital stays. Troponin I is related to an increased mortality rate.

The structural damage to myocardial cells was demonstrated in our study, confirming significant increases of CKMB and cTn I at intervals 2 and 3 for both the Preconditioned and Control groups. It is possible that silent myocardial ischemia had occurred which was not clinically demonstrated in the postoperative period, by serial electrocardiography, by hemodynamic alterations or by the presence of angina.

The ischemic Pre-conditioning of the heart is a paradoxical phenomenon, in which a short period of ischemia confers resistance to a subsequent period of ischemia in the myocardium.

Initially reported by MURRY et al. [5] in 1986, preconditioning was described as a period of myocardial ischemia followed by sanguineous reperfusion, after which a greater period of ischemia was provoked, causing localized myocardial infarction. It was observed that with preconditioning the area of myocardial necrosis was smaller.

Based on experimental studies of pre-conditioning, it is believed that there is a benefit on human hearts of preconditioning. The phenomenon was observed by DEUSTCH et al. [18] in patients with arteriosclerotic coronary disease who were submitted to coronary angioplasty, as when they are insufflated previously, parameters such as pain during the procedure and alterations of the ST segment were observed with at a lower frequency.

YELLON et al. [19] in a clinical work on preconditioning in patients submitted to CABG, reported the preservation of the ATP in subsequent periods of ischemia, indicating ischemic tolerance of the human myocardium.

The Control group had a statistically greater increase 
of cTn I, at the end of CPB than the Preconditioned group in this study of 29 patients with long-term follow-up. The use of preconditioning has been demonstrated as a predicting factor of myocardial lesions, which was also confirmed in this study. However, the sensitivity of CKMB to show the difference of myocardial lesion or microinfarctions for the Control and Precondition groups could not be demonstrated. RAEBURN et al. [20] observed a trend of lesser myocardial lesions during CABG in patients who underwent preconditioning. The benefit of preconditioning was demonstrated in the patients of our cohort. The greater incidence of cardiovascular symptoms was strongly biased for individuals of the Control group who were not submitted to preconditioning. Nevertheless, there was no statistically significant difference ( $\mathrm{p}$-value $=0.09$ ).

The patients of the symptomatic Control group presented with cTn I measured at the end of CPB of 5.07 $\pm 3.69 \mathrm{ng} / \mathrm{dL}$, which was significantly higher than the other groups. This group had a good immediate postoperative evolution, however later reported with a greater frequency of heart disease symptoms. The value of CKMB was not different in this group when compared to the others.

The measurement of cTn I, at the end of CPB, was higher both in the Control group or Preconditioned group demonstrating that in the intraoperative period there is myocardial lesions not evidenced by other methods. The Preconditioned group in this series of patients, showed they were benefited in relation to the Control group by a lower increase of cTn I.

The patients of the symptomatic Control group in the follow-up period were those who presented with higher levels of cTn I at the end of CPB.

It is possible that the increase of cTn I observed in samples collected from the coronary sinus are a marker of late evolution in patients submitted to $\mathrm{CABG}$.

\section{CONCLUSIONS}

The Preconditioned group benefited with the lower liberation of cTn I. In the follow-up period there was no significant difference in the presence of cardiovascular symptoms in relation to the Control group $(p$-value $=0.09$ )

Troponin I collected in the coronary sinus at the end of CPB might be a marker for cardiovascular events in CABG surgeries.

\section{BIBLIOGRAPHIC REFERENCES}

1. Slogoff S, Keats AS. Does perioperative myocardial ischemia lead to postoperative myocardial infarction? Anesthesiology 1985; 62:107-14.

2. Jain U, Wallis DE, Moran JF. Significance of eletrocardiographic ST elevation during coronary artery bypass surgery. Anesth Analg 1994; 78: 638-43.

3. Adams JE, Sicard GA, Allen BT, Bridwell KH, Lenke LG, Davila-Roman VG et al. Diagnosis of perioperative myocardial infarction with measurement of cardiac troponin I. N Eng J Med 1994; 330: 670-4.

4. Bonnefoy E, Chevalier P, Kirkorian G, Guidolet J, Marchand A, Touboul $\mathrm{P}$ et al. Cardiac troponin I does not increase after cardioversion. Chest 1997; 111: 15-8.

5. Murry CE, Jennnings RB, Reimer KA. Preconditioning with ischemia: a delay of lethal cell injury in ischemic myocardium. Circulation 1986; 74: 1124-36.

6. Pêgo-Fernandes PM, Jatene FB, Kwasnicka K, Hueb AC, Moreira LF, Gentil AF et al. Ischemic preconditioning in myocardial revascularization with intermittent aortic crossclamping. J Card Surg 2000; 15: 333-40.

7. Kilger E, Pichler B, Weis F, Goetz A, Lamm P, Schutz A et al. Markers of myocardial ischemia after minimally invasive and conventional coronary operation. Ann Thorac Surg 2000; 70: 2023-8

8. Admas JE, Bodor GS, Davila-Roman VG, Delmez JA, Apple FS, Ladenson JH, et al. Cardiac troponin I: a marker with high specificity for cardiac injury. Circulation 1993; 88: 101-6.

9. Tatschl C, Fazekas T, Hammerle AF. Relevant markers of the acute coronary ischemic syndrome. Acta Anaesthesiol Scand 1998; 42:92-9.

10. Etievent JP, Chocron S, Toubin G, Taberlet C, Alwan K, Clement $\mathrm{F}$ et al. Use of cardiac troponin I as a marker of perioperative myocardial ischemia. Ann Thorac Surg 1995; 59: 1192-4.

11. Swaanenburg JC, Loef BG, Volmer M, Boonstra PW, Grandjean JG, Mariani MA et al. Creatine kinase MB, troponin I release patterns after coronary artery bypass grafting with or without cardiopulmonary bypass and after aortic and mitral valve surgery. Clin Chem 2001; 47: 584-7.

12. Piper HM, Schwartz P, Spahr R, Hutter JF, Spiekermann PG. Early enzyme release from myocardial cells is not due to irreversible cell damage. J Mol Cell Cardiol 1984; 16: 385-8. 
13. Raman JS, Bellomo R, Hayhoe M, Tsamitros M, Buxton BF. Metabolic changes and myocardial injury during cardioplegia: a pilot study. Ann Thorac Surg 2001; 72:1566-71.

14. Costa MA, Carere RG, Lichtenstein SV, Foley DP, de Valk V, Lindenboom $\mathrm{W}$ et al. Incidence, predictors and significance of abnormal cardiac enzyme rise in patients treated with bypass surgery in the arterial revascularization therapies study (ARTS). Circulation 2001; 104: 2689-93.

15. Jenkins DP, Pugsley WB, Alkhulaifi AM, Kemp M, Hooper J, Yellon DM. Ischaemic preconditioning reduces troponin $\mathrm{T}$ release in patients undergoing coronary artery bypass surgery. Heart 1997; 77:314-8.

16. Greenson N, Macoviak J, Krishnaswamy P, Morrisey R, James $\mathrm{C}$, Clopton $\mathrm{P}$ et al. Usefulness of cardiac troponin I in patients undergoing open heart surgery. Am Heart J 2001; 141: 447-55.
17. Antman E, Tanasijevic MJ, Thompson B, Schactman M, McCabe $\mathrm{CH}$, Cannon $\mathrm{CP}$ et al. Cardiac-specific troponin I levels to predict the risk of mortality in patients with acute coronary syndromes. N Eng J Med 1996; 335:1342-9.

18. Deutsch E, Berger M, Kussmaul WG, Hirshfeld JW, Herrmann $\mathrm{HC}$, Laskey WK. Adaptation to ischemia during percutaneous transluminal coronary angioplasty: clinical, hemodynamic, and metabolic features. Circulation 1990; 82: 2044-51.

19. Yellon DM, Alkhulaifi AM, Pugsley WB. Preconditioning the human myocardium. Lancet 1993; 342: 276-7.

20. Raeburn C, Cleveland J, Selzman CH, Harken AH. On "ischemic preconditioning in myocardial revascularization with intermittent aortic cross-clamping" (Invited Commentary). J Card Surg 2000; 15: 339-40. 